\title{
A Study on The Effects of Internet Websites Use on Local Identity: A Case Study on Local Students of Isfahan University
}

\author{
Mohammadreza Hafiz Nia1 \\ Zahra Ahmadi Poor2 \\ Keramat Ranjbar ${ }^{3}$ \\ 1 Professor at Tarbiat Modarres University \\ ${ }^{2}$ Associate Professor at Tarbiat Modarres University \\ ${ }^{3}$ MA at Tarbiat Modarres University (Iran) \\ E-mail:K.ranjbar110@gmail.com,Hafezn_m@modares.ac.ir, Ahmadyz@modares.ac.ir
}

Doi:10.5901/mjss.2016.v7n4p

Abstract

Derived identities in the real space bear certain connotations which lead in a sense of localism Place, an important point is that in spite of existence of internet websites which open the entry to a virtual space for the individuals, they may create new identities and challenge the real identities. The current study aimed at evaluating the effects of internet websites on the local identity of Isfahan University students, using a sample size of 281 local students in Isfahan City. The results of the study indicated that internet websites have not a significant effect on local identity of students in Isfahan City.

Keywords: local identity, internet websites, local students in Isfahan City

\section{Introduction}

Identity means "who are you", that how an individual or human group knows himself/itself and how he wants to be introduced and known by others. Identity is a response to the natural need of human for introducing himself to a series of elements and cultural, historical, and geographical phenomena (Mojtahed Zade, 2007). On the other hand, the network policy (internet reduces the costs of distributing information and controls which is named network policy) has a dynamic and effective background in soft affairs such as moral legitimacy, cultural identity, social values and public recognition and even the erosion of nation-states in the geopolitical sphere is believed to be a result of this type of information and communication technologies (Hafez Nia, 2006). Also, the places are important sources of individual and group identity create a centrality in which deep emotional and psychological ties exist between the people (Shokouei, 1996). National, local, and settlement affiliations even in long trips are rarely dissipated and there are few people who do not desire to return to their homeland after years of being away from home. Place attachment besides patriotism and nationalism make individuals' identity (Hafez Nia, 1999). Despite the many significant changes resulted from globalization all over the world, the current realities indicate that most types of cultural specific-orientations are not also disappeared or faded, but also they are even somehow reiterated more than ever (Smith, 2005).

Place-derived identities in real space bear a special connotation that in itself can be manifested in emergence of sense of attachment to the place, though the important point is that regarding the existence of the internet and using this means, an entry is opened for people which can create new identities and challenge the real identities. The main question of the current study is that whether the use of internet affects local identity?

\section{Theoreticai Framework}

\section{1 concepts}

Internet: internet, in the simplest definition, is a set connected computers all over the world, the netwprk which connects these computers, and data transfer method on this network (www.doctionary.com).

Web or website: web is the most common and most important use of internet. The concept of internet can be somehow summarized in web. Website is a set of all pages with a specific address which can be observed by the users 
(mahadavi, 2005).

Internet user: generally, a person who searches, studies, educates, entertains, and does any other things through the internet is called internet user. There are a variety of international standards for the definition of Internet users and in general, an internet user can be defined from two aspects of connection and time as follows:

The one who has internet connection (computer and modem)

The one who can use internet for example X hours per week (Fatemi, 2009).

The definition of Internet penetration coefficient: unfortunately, there are no precise and scientific definitions of internet penetration coefficient in the country and this is the reason behind the differences in providing internet penetration percentage. Sharif Industrial University has provided a formula which under assessment by experts and professionals, which will be the most scientific definition in case it is approved (www.sharif.ac.ir).

Social Networks: Social networks are a new generation of databases that are nowadays the focus of worldwide Internet network users. Social networks are a kind of social media which enable a new form connection and file sharing on the internet (Broogman, 2010). While these networks are spaces in which people find new friends or inform their old friends about changes in their lives, they are also places in which young people share ideas and opinions. This capability that a young person can communicate with his peers in other countries allows these networks to become a place in which new ideas are introduced and discussed. Social networks among the networks quickly developing on the internet and indicative of an abnormal phenomenon called increasing social credit (Waters, 2007).

Local sites: the sites on topics such as local and regional news, information, events and interests of a city or village's limited geographical environment.

Identity means "who are you", that how an individual or human group knows himself/itself and how he wants to be introduced and known by others. The identity is a response human's natural need for introducing himself to a set of elements and cultural, historical, and geographical phenomena such as common land, common religion, a common language, common political memories, visions, customs, common forms of literature and art. However, firstly it is the fruit of geographical environment (Mojtahed Zade, 2007). Richard Jenkins puts it as follows: referring to the Oxford English dictionary, we find that the word identity roots back in Latin and has two major meanings: the first meaning is indicative of absolute similarity (this is similar to that). The second meaning is indicative of differentiation which is assumed by him as consistency and continuity. Thus, he finds the concept of similarity in two different angles and makes two probable connections simultaneously between people or objects. On the one hand resemblance and on the other, difference. Identity is not available by itself, rather it should be consolidated. This adds another two matters to our list: one is categorization of people and objects, and the other is connecting us with something or someone else.

Undoubtedly, this understanding of self and others may not be accomplished without a meaning making process. As Manuel Castells puts it, identity is the process of construction of meaning on the basis of a cultural attribute or a set of cultural characteristics that are superior to other sources. In his opinion, as roles organize special works, the identities also organize meaning in the same manner. From this viewpoint, identity is a concept that combines the internal or personal world with a public space of cultural formations and social relationships. Identities are key meanings forming the individuals' mentality and through which people become sensitive about their life environment events and changes. People tell others who they are and more importantly, they also tell themselves who they are and try to behave in a way how they are expected to (Tajik, 2005).

National identity: national identity is a set of common features and values of an independent nation to which the citizens have self-recognition and through which they feel attached to each other. National identity distinguishes one nation from another ne and paves the way for its introduction. Although the territorial, racial, cultural, religious and other characteristics are effective on the formation of national identity, these values may not be specific to a national government and may exist in other government $\mathrm{s}$ and nations in a way or another. Therefore, the national identity may be a set of institutions in which the values belonging to some people community are determined (hafez $\mathrm{Nia}, 2008$ ).

Local identity: local identity is sporadic images that when put together, a big picture named national identity is created (Rostami, 2008). Also, local-orientation and localization means considering the neighborhoods as the center of people's local life (Kaviani Rad, 2005).

\subsection{Theories of identity and internet}

It seems the identity (personal, public, and national) is the product of social interaction. Therefore, when the identity is the product of social interaction, variability, fluidity, and relativity states are among its properties. When the identity takes an artificial state, it is the dominant powers that make identity and try to maintain them. Regarding the fact that identities are social constructs, it can be said that the social construction of identities always takes place in the context of power 
relations. What factors are effective in challenging the identity and making it critical? For answering this question, various factors and assumptions can be provided. One of the most important factors effective on identities (personal, public, and national) nowadays, and somehow has formed it, is the changes resulting from modern information and communication technologies (Mir Mohammadi, 2004).

Anthony Giddens emphasizes on the individual's role in formation of identity and defines it as recognition of the person of his "self". Giddens interpretation of identity is close to Kahn's identity. In this interpretation also both social and individual aspects are included, though more emphasis is put on individual aspect and the person's role in the modern world in formation and reconstruction of identity besides the dynamic and variable aspect of identity. Giddens has considered and analyzed the psychological aspect and identity challenges in the modern era and accounts rethinking in identity which takes place in the shade of modern norms and values which are constantly changing, as a characteristic of new era and the result of development of information and communication technology and economic and cultural globalization (Giddens, 1999).

John Fedder speaks of a revolution taken place in terms of information and communication worldwide and affected the humans' lives all over the world. A revolution based and dependent on computers, having extensive economic, political, and cultural effects. It means that on one hand, the information has turned into a commercial and profitable commodity that gives power and on the other hand has lasting effects on man's personality and identity (Feder, 2001).

Several radio and TV channels, various internet websites, thousands of mass media and press, advertising and promotional wall, various magazines and books, all show the influence of cultural intelligence. However, these effects are not limited to them, the clothes we wear, our hairstyle, the food we eat, etiquette, and our houses architecture, are also noteworthy on this matter. Contemporary culture strangely includes the information and values of past and other cultures and uses them (Webster, 2003).

Jurgen Habermas as one of the most prominent theorists has criticized the emergence of satellite and digital information technology and its impact on the process of globalization. In his opinion, although the most important aspect of globalization is economic globalization, there has also been a trend of specific cultural products in cultural aspects which led to a type of consistency between the cultures. He believes that culture is now an American product, imposing itself not only on distant lands, but also weakening commodity culture has not only imposed on distant lands, but also fading most meaningful differences and weakening deep-rooted local tradition even in the West (Habermas, 2005).

Habermas also in his famous work "The structural transformation of the public sphere" has dealt with the emergence of public sphere and states that information is the central core of public sphere and mass media and informational institutes play a role on creation and extension of this sphere. But in the late twentieth century, dominance of utilitarian thoughts of economic institutions and polarization of the rule of international powers, economic globalization and privatization, resulted in the destruction of the "public sphere". As a result, some of the data are no longer available to the public and a mass product-oriented culture is being promoted. Habermas believes that resolving this problem depends on the development of a communicative rationality and weakening instrumental rationality and tries to promote a theory and solution for communicative action at the community level, since the human identity and attitude is formed only through communicative action path and get distant from an instrumental and metamorphosis state and frees them from an equalizing mass culture dominance (Webster, 2003).

\subsection{Internet and Social Identity}

Today, few people doubt on the proposition that the world has entered a new era that symbolized the importance of the information. Many scientists and social science experts believe that the combination and integration of communication technologies and the restructuring of capitalism in recent decades enters us in a new era and community. Daniel Bell's defines it as post-industrial society, Manuel Castells calls it network society and Tadao Sao names it information society. Information society is where access to information is increased and it has a great importance in routine life and causes changes in occupational structures. Due to extension of the influence of the mass media, especially satellite and the Internet and other communication technologies, today the information society has taken a universal aspect and is not limited only to particular country or countries (Shakouri, 2008).

\subsection{Internet Websites and its Connection with Local Identity}

Internet websites are among the most extensive constituent elements of the internet and also an effective factor on local identity besides other factors. According to Giddens theory, it can be concluded that these websites are the product and creature of meaningful interactions between the humans and people create such environment. However, after formation 
of this environment, it imposes some limitation on its operators. Also, the websites endure based on reproduction or repetition of the same humans' continued behavior. Unlike conventional media, people do not simply fit in the category of producers or consumers when facing internet, but they are optional to take both roles simultaneously and produce and reproduce, though some act and cooperate differently facing this structure. In fact, the more the people are active and take part facing internet, and the more these activities are reflective, they have more share in producing meaning and as a result, they are more influenced. On the contrary, the less the people are active and take part facing internet, and the less this activity is reflective, they have lower share in reproducing the meaning and as the result, less influenced. The level to which Iranian users are influenced by internet and virtual space depends on factors and variables such as the type of Internet use, motivation and target of users using the Internet, participation and activity of users of the Internet, assuming the content of the internet as real, and also the users socio-economic status and education.

\section{Methodology}

This study enjoys an approach utilizing library and electronic sources. It aims to illustrate anything and to explain and determine the effects of websites on the local identity. By delving into the literature and research's theoretical foundation, propositions and general statements are specified and theories are formulated employing a descriptive approach. To analyze the data, to test the hypothesis and to deduce conclusions from the findings obtained from the research, an analytical approach is adopted. On the whole, this paper is built on descriptive-analytical methods. The ultimate goal of the paper is to clarify issues for the decision-making and programming for the competent organizations in the future. The necessary data for the evaluation of the hypothesis were gathered through a 20-item questionnaire measuring the effects of the use of websites on the local identity of students who are from Isfahan and studying at University of Isfahan. This survey utilized a likert scale to measure the attitudes of the respondents on a range of five responses available to them. Having applied the Cochran formula to calculate the sample size, 281 students were chosen from University of Isfahan. The data analysis was generated using the SPSS software program. The research question was:

What are the effects of internet websites on local identity?

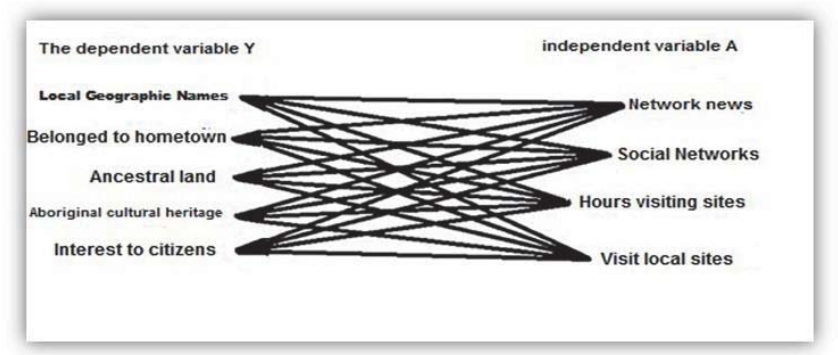

Figure 1. 2: And the conceptual model of the study is as follows

\section{Data Analysia}

The results are obtained based on the questionnaire's responses as follows.

In terms of gender distribution, $70 \%$ of the participants were female and 30\% were male. Education: $70 \%$ were graduate students, $10.9 \%$ were post-graduate students, and $0.9 \%$ were Ph. D students. Employment: $19.1 \%$ were employed, $68.2 \%$ unemployed, and $12.7 \%$ no response. Marital status: $71.8 \%$ were single, and $22.7 \%$ were married, and $5.5 \%$ no response. Membership in social networks status: 23.25 in Facebook, $0.9 \%$ in twitter, $306 \%$ in YouTube, and $7.3 \%$ in other social networks. $56.8 \%$ of the participants were not a member of any social networks. Internet use rate: $27.7 \%$ once in a month, $40 \%$ once or twice a week, 15.5\% 4-5 days a week, and 15.9\% 6-7 days a week. The participants' internet websites use status: 16.4 news websites, $25 \%$ social networks, $8.6 \%$ local sites, and $43.6 \%$ other websites. Internet website types: $15 \%$ for getting news from foreign websites, $16.8 \%$ for local websites, $16.8 \%$ for news websites, $23.2 \%$ for visiting their own social networks, and $7.3 \%$ for entertainment. News websites attraction: $64.1 \%$ for Iranian websites, $6.4 \%$ for CNN, $15.9 \%$ for BCC, $5 \%$ for VOA. $8.6 \%$ of the participants did not answer this question. Internet Use Rate: $27.7 \%$ participants who used internet once a month, and $71.1 \%$ participants who used internet once a week. 
Social networks membership: $43.6 \%$ of the participants are a member of social networks and $56.8 \%$ are not a member of social networks.

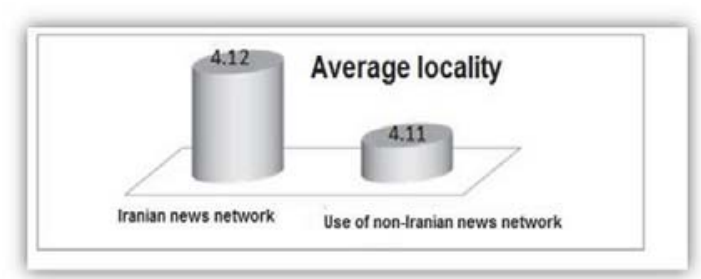

Figure 1. 3: The mean score of Iranian and foreign news website users local-orientation: $4.12 \%$ using Iranian news websites, and $4.11 \%$ using foreign news websites.

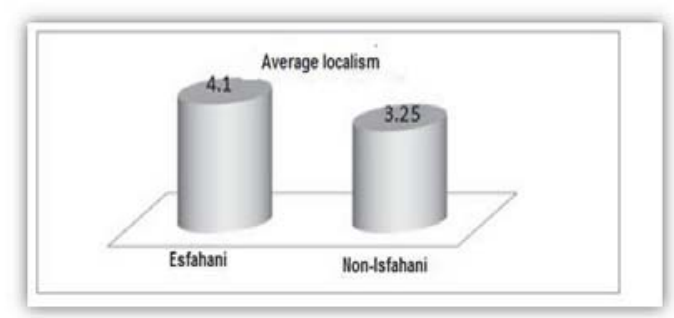

Figure 2. 3: The mean score of local-orientation of Isfahan and non-Isfahan students: $4.1 \%$ Isfahan and 3.25\% nonIsfahan

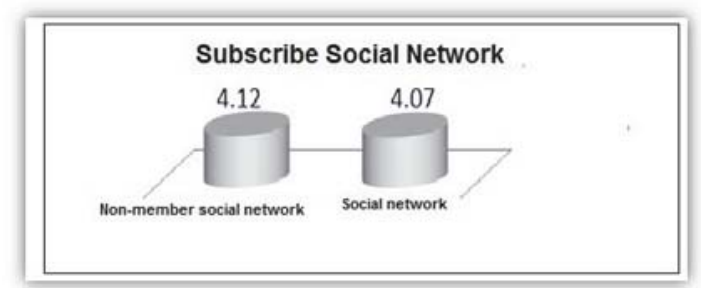

Figure 3.3: Mean score of local-orientation of social networks members and non-members: $4.07 \%$ are members of social networks. $4.12 \%$ are not members of social networks.

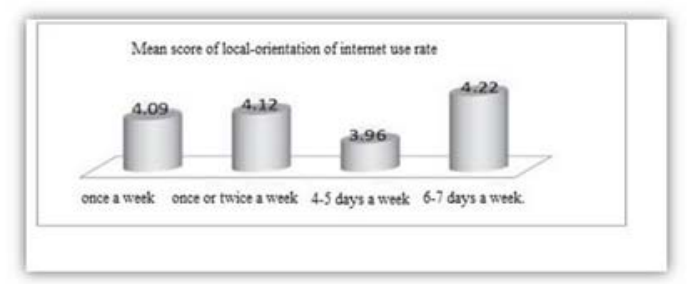

Figure 4.3: Mean score of local-orientation of internet use rate: 4.09\% once a week, 4.12\% once or twice a week, 3.96\% 4-5 days a week, and $4.22 \%$ 6-7 days a week.

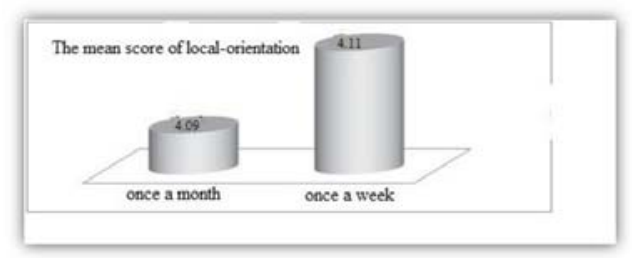

Figure 5.3: The mean score of local-orientation for once a month and once a week: 4.11\% once a week, and 4.09\% once a month. 
Internet websites lead in the increase of local-orientation sense.

For evaluating whether internet websites increase local-orientation, 20 elements were proposed based on conceptual model and relationships between variables, some of which specific to internet websites and some specific to local-orientation variables.

$\mathrm{H} 0$ and $\mathrm{H} 1$ hypotheses are as follows:

$\mathrm{HO}$ : there is no significant difference between internet website use and local identity.

$\mathrm{H} 1$ : there is a significant difference between internet website use and local identity.

According to ANOVA test results; there are no significant differences between users of social networks, local sites, news channels and hours of Internet use and geographic names, attachment to the homeland, the ancestral land, indigenous cultural heritage and interest in fellow-citizens.

The $p$ value (0.416) is higher than $\alpha(-0.5)$.

Table 1::3 ANOVA test for local-orientation, local websites, new websites

\begin{tabular}{|l|c|c|c|c|c|}
\hline & Total squares & Degree of freedom & The mean squares & F distribution & Significance level \\
\hline Inter-groups & .812 & 3 & .271 & .953 & .416 \\
Intra-groups & 57.429 & 202 & .284 & & \\
& & & & & \\
& & & & & \\
\hline
\end{tabular}

So, the null hypothesis is approved and as the result:

There is no significant difference between internet websites use and local identity and the hypothesis is rejected.

\section{Conclusion}

Identity is derived from people's self-recognition and this self-recognition is acquired from environment and heredity. Who am i? Who are my parents? Where do I live? Am I attached to a specific tribe, religion, language, and culture? Are the basic questions everybody needs for recognizing his "self" in geographic and social environment, in order to introduce himself to others and t be known through those identities.

The local identity is a product of the person's recognition of environment, birthplace, and growing with traditions, interest, and attachment to living place. Also, the people in a geographical environment cause attachment and dependence to each other through their interactions with each other. Therefore, all the shared points in a limited geographical environment with common interests create a small identity which is called local identity. The local identity is important in that it creates a small part of the big image of national identity and is the foundation for national identity.

The results of the current study indicated that there is no relationship between internet website users and local identity, and these sites and their subsets do not affect the local identity of the internet users. Also, it was revealed that there is no significant difference between mean score of local-orientation of the internet users and others.

Therefore, it seems the Iranian society is not still in the place for it the internet can be considered as a very important instrument for changing or affecting the users' local identity, since Iranian society is in the transition phase and using this structure in Iranians' lives is in the initial phases.

\section{References}

Broogman, Y., (2010), "an introduction to social networks", translated by Mirzayi, KH, Jame Shenasan Publications, Tehran.

Castelles, M., (2001), "network society and information era", 2nd Ed, Translated by Chavoshian, H., Tarhe Now Publishers.

Castelles, M., (2001), "network society and information era", 1st Ed, translated by Aghilian, A., \& Khakbaz, A., Tarhe Now Publishers.

Fatemi, M.A., (2009), "the internet", Ebtekar Danesh Publishers, Tehran.

Fedder, J., (2001), "informational society", translated by Radbaveh, A., \& Gilverdi, A., 1st Ed, Ketabdar Publications

Hafeznia, MR and others (2006), the impact of globalization on national identity. Journal of Geopolitics. The third and fourth numbers; Tehran: Geography Organization

Hafeznia, MR (1999), the principles and concepts of geopolitics, Tehran: Astan Quds Razavi

Hbermas, H., (2005), "the structural modification of public sphere", translated by Mohammadi, J., 1st Ed.

Kaviani Rad, M., (2005), "the effects of globalization on national identity", political geography doctoral thesis, Tarbiat Modares Tehran University.

Mahdavi, M.H., (2005), "the comprehensive dictionary of internet and web", Millenium Publications, Tehran. 
Mir Mohammadi, D., (2014), "introduction to national identity in Iran", Iranian Civilization Publications, Tehran.

Mojtahed Zade, P., (2007), "political geography and geographical politics", SAMT, Tehran.

Mojtahed Zade, P., (2007), "democracy and Iranian identity", Kavir Publishers, Tehran.

Morshedi Zade, A., (2010), "the Azeri elite attitudes towards national and regional identity", a doctoral thesis, faculty of law and political sciences, Tehran University.

Ritters, J., (1998), "the theories of sociology in the contemporary era", translated by Salasi, M., Elmi Publishers.

Rostami, F., (2008), "the share of local identities in formation of national identity", Zamaneh Magazine, No. 67-8.

Sharafi, M.R., (2002), "the youngsters and identity crisis", 3rd Ed, Sporoush Publications

Shokouei, H., (1998), "new thoughts in philosophy of geography", 1st Ed, Gitashenasi Publishers, Tehran.

Shokouei, H., (2009), "new thoughts in philosophy of geography; environmental philosophies and geographical schools", 2nd Ed, Gitashenasi Publishers, Tehran.

Tajik, M.R., (2005), "the identity", journal of national studies, Tehran.

Tajik, M.R., (2005), "the story of strangeness and identity among Iranians", Farhang Gofteman Publishers, Tehran.

Smith, A, (2005) In Encarta Referenceencyclopedi

Waters, S., (2007), "internet and its social abnormalities", translated by Mashayekh, M., Amir Kabir Publishers, Tehran.

Webster, F., (2004), "the theories of informational society", translated by Ghadimi, E., 2nd Ed., Agar Publishers.

www.dictionary.com

www.sharif.ac.ir

www.yjc-isf.ir 